\title{
A new editorial board for new challenges
}

\author{
WaGner F. GatTAZ1, José A. S. CRIPPA² \\ 1 Institute of Psychiatry, University of São Paulo Medical School (FMUSP), São Paulo, SP, Brazil. \\ 2 Department of Neuroscience and Behavior, Ribeirão Preto Medical School, University of São Paulo (FMRP-USP), Ribeirão Preto, SP, Brazil.
}

Received: 5/30/2017 - Accepted: 5/30/2017

DOl: 10.1590/0101-60830000000119

Gattaz WF, Crippa JAS / Arch Clin Psychiatry. 2017;44(3):55

It is with mixed feelings of gratefulness and renewed energy that we announce the new editorial board of the Archives of Clinical Psychiatry. At the same time that we say goodbye to some of the editors who have given life to our journal over the past years, we cheerfully welcome our newly arrived associate editors, who accepted the challenge of continuing and expanding the fine work done until now.

The entrance of our new Editor-in-Chief, Dr. José A. S. Crippa, from the Medical School of the University of São Paulo in Ribeirão Preto, was the first step to bring together the two centers of research in psychiatry and neuroscience of the University of São Paulo with the purpose of strengthening and expanding the relevance and visibility of the Archives of Clinical Psychiatry. Now, each of the five areas covered by our journal will be headed by two associate editors, one from São Paulo and one from Ribeirão Preto.

We would like to express our deepest thanks and appreciation to Dr. Clarice Gorenstein, former Associate Editor of the area of Instruments and Scales, Dr. Francisco Lotufo Neto, former Associate Editor of Human Sciences, and Dr. Geraldo Busatto Filho, former Associate Editor of the area of Clinical Psychiatry. Please receive our deepest gratitude for the time and effort put into the development of our journal over this period.

To share the responsibility for the area of Child and Adolescent Psychiatry with Dr. Guilherme Polanczyk (FMUSP), we welcome Dr. Maria Beatriz Linhares (FMRP-USP). Dr. Jaime Hallak (FMRP-USP) now takes over the area of Clinical Psychiatry together with Dr. Tânia C. F. Alves (FMUSP). Drs. Elaine Henna (FMUSP) and Flávia Osório (FMRP-USP) are now our associate editors for the area of Instruments and Scales, and Dr. Marcos H. N. Chagas (FMRP-USP) has joined Dr. Orestes Forlenza (FMUSP) as associate editor for Neuroscience. Finally, we welcome Dr. Clarissa Corradi-Webster (FFCLRP-USP) and Dr. Julio Peres (FMUSP) to head our former area of Human Sciences, under the new name of Psychology and Psychotherapy.

In its $45^{\text {th }}$ anniversary, the whole staff of the Archives of Clinical Psychiatry is happy to rely on the solid basis established by our past contributors and to count on the expertise and enthusiasm of our new editors to become a top-ranking journal in its field and to contribute for the furthering of Brazilian and world science. 